\title{
How Much!? Determining the Cost of an Assignment in an Organic Chemistry Class
}

John Kromer ${ }^{\mathrm{a} *}$

${ }^{a}$ University Library, Arizona State University, Tempe, $A Z$

601 E. Tyler Mall

PO Box 871006

Tempe, AZ 85287-1006

*Note: Research was conducted while author was a librarian at Miami University. 


\title{
How Much!? Determining the Cost of an Assignment in an Organic Chemistry Class
}

\author{
Students in Organic Chemistry for Majors were required to write a paper as the \\ culminating course assignment. Prior to completing this assignment, students \\ could attend a library instruction session covering relevant databases and \\ resources. Upon submission of their papers, bibliographies from 53 students were \\ collected. Calculations were made to attempt a holistic account of costs \\ associated with completing the assignment. Factors such as the cost of journals, \\ databases, and librarian time were all included in the overall cost estimate, \\ totalling $\$ 7,189.22$ for this single assignment.
}

Keywords: cost analysis; resource costs; service costs; STEM education; chemistry education; academic libraries

\section{Introduction and Background}

In the age of rising journal prices and flat or falling budgets, every purchase and ongoing subscription must be justified. University budget models continue to evolve as well, and libraries are increasingly viewed as "cost centers", which puts further pressure on library administrators to defend their budgets. Librarians often rely on total cost, cost per use, or student achievement when trying to explain the need for a particular resource, but rarely if ever has a library/librarian tried to show a holistic picture of the value that the library provides for a particular class or assignment. This study attempts to combine all relevant factors (database cost, journal cost, and librarian cost) into a single value for the services that the library provided directly to a single class. If this study were to be expanded to include all the classes for a single department, or even more broadly to encompass all the classes in the university, administrators would likely be able to see just how valuable the library "cost center" is to the academic life of the university. 
Eileen G. Abels (1997) and Paul B. Kantor, Tefko Saracevic, and Joann D'Esposito-Wachtmann (1995) have provided excellent frameworks for calculating library costs. Abels introduces some important caveats in conducting cost analyses of reference and instruction services. She writes: "The average unit cost approach calculates the costs of output units of individual services, such as the answering of a reference request or the conducting of an instruction session. It is impossible to cost an individual service accurately if that service cannot be differentiated from other services." This and other considerations are presented throughout her paper, as is a review of existing library cost studies, making this a pertinent read for anyone looking to undertake a cost analysis of library services (1997). Kantor, Saracevic, and D’Esposito-Wachtmann similarly present frameworks and suggestions for conducting costs analyses and offers several case studies, but none of these articles look explicitly at library instruction (1995).

While cost analyses of library services have long been a staple in the library literature, very few look at the cost of instruction. Some notable exceptions are those presented by Nancy L. Eaton and Nancy B. Crane (1987), Marianne Broadbent and Hans Lofgren (1993), Lynn Scott Cochrane and Carolyn Warmann (1989), Carol C. Spencer (1980), Carol Hansen Montgomery (2002), and Anthony W. Ferguson and John R. Taylor (1980).

The most similar study to the one presented here was done by Eaton and Crane, in which they calculated the cost of a librarian developing training modules to help patrons conduct their own searches. They compared this with the cost of a librarian doing in-person presentations and found that the modules did result in significant 
savings to the library over in-person presentations. Ultimately they used this information and other contributing costs to justify the creation of an "Automated Reference Center" where patrons could go to get on-demand training modules (1987).

Broadbent and Lofgren were similarly exploring the costs and benefits of providing a new service, and they calculated the cost of a librarian's time to deliver training if the new service was not offered and users had to do the task themselves (1993).

Spencer, Ferguson and Taylor, and Montgomery each looked at the hours that librarians spent on different types of tasks, of which instruction was one task. Spencer and Ferguson and Taylor kept instruction as an independent task, whereas Montgomery rolled it into "information services" and "systems operations" headings, making it impossible to separate out which tasks were specifically dedicated to instruction (Montgomery 2002). Ferguson and Taylor chose not to assign dollar values (salary) to each task (1980), which leaves Spencer as the most useful of these studies, in terms of getting both time and relative value of providing information services (1980).

Cochrane and Warmann conducted a library-wide cost analysis to determine which departments could potentially be converted to a fee-based service. They attempted to capture every factor contributing to a service's cost, including direct costs, overhead, and administrative salaries. One of the major categories they explored was library instruction, which they calculated in total and further to the level of cost per individual and cost per group of each instruction session (1989). 
What is missing from each of these studies is the narrow focus on a single discipline, coupled with the comprehensive inclusion of both librarian and resource cost. Considering the drastic difference in resource costs across disciplines (Bosch and Henderson 2015), the blanket approach taken by existing studies does not explore the nuance that can be introduced in individual disciplines, particularly one as expensive as chemistry. The study described below attempts to expand on the limited body of research in order to include journal, database, and librarian salary when calculating costs for providing the resources necessary to complete a second-year chemistry assignment.

\section{Methods}

\section{Data Collection}

Students in Chemistry 254: Organic Chemistry for Majors were required to write an article about a name reaction (that is, a reaction named after the person who discovered it). Once the students submitted their papers, their bibliographies were collected and anonymized. The librarian checked articles to make sure that the citations were complete and correct, including making sure the student cited the correct journal— which, though seemingly obvious, was a mistake discovered far too often. The resulting list contained 465 total citations, of which 419 were articles. The remaining citations were primarily to websites, a resource that the course instructor expressly forbade students to use and that furthermore did not cost anything for the library to provide.

\section{Journal Usage}

For each article in the list, 2013 usage statistics were checked. Miami University is in a somewhat unique position in that some journals have usage statistics reported in two 
places: access through OhioLINK (a statewide academic library consortium) and its Electronic Journal Center, and local access through the publisher's website or through local databases. Care was taken to get usage statistics from both locations, and the total (combined) usage statistics were used for the purpose of this study.

\section{Journal Costs}

Where possible, actual cost was used for journals in this study. These journals were those that Miami University purchased directly from the publisher. However, this data was unavailable in most cases, primarily because the journals were included in subscription packages and not priced individually. For journals in these packages, prices were obtained from publisher lists for individual titles if possible. Finally, for those journals where prices were not available as actual costs or as list prices, prices listed in Ulrichsweb ("Ulrichsweb.Com" 2014) were used.

For those journals in packages, the overall cost of the package (actual price paid) was collected.

\section{Journal Cost per Use}

Cost per use was then calculated: cost of the journal (obtained through whichever method listed above) was divided by the total use of that journal for the year. Each article cited by a student was one use of the journal, so the cost per use of that journal was assigned to the citation. These costs were summed, resulting in a "total journal cost (List Price)" for the assignment.

For those journals in packages, the cost per use was calculated for the overall package: cost of the entire package divided by the total use of the package. In this second sum, the price from the packages replaced the list price and Ulrichsweb costs, as 
the package cost more accurately reflected the cost paid for these articles. This sum resulted in a second "total journal cost": Actual Price.

\section{Total Journal Cost}

While 419 of the citations across the students' papers were for articles, only 365 of them could be verified enough to determine a cost for the journal, due to the incomplete or inaccurate nature of the remaining citations. Using the List Price cost per use, the total value of all the articles that students cited was $\$ 12,008.78$ (mean cost per use $\$ 32.90$, median cost per use \$4.25). Twenty-eight (28) of these articles were open access articles, which did not change the total list price cost, but brought the mean cost per use to $\$ 35.63$ across all non-open access journal citations.

List price was a large over-estimate for the actual cost of the journal articles, because Miami University's participation in OhioLINK resulted in savings of $\$ 9,696.92$, for an Actual Cost per use of \$2,312.71 (mean cost per use $\$ 6.86$ when excluding open access articles).

\section{SciFinder Cost per Session}

Prior to submitting this assignment, students were given the option of attending a library instruction session, where they were shown how to use SciFinder to find articles and spectra and encouraged to use it in completing their assignment. Cost for SciFinder was the actual amount Miami University paid for SciFinder access in 2013.

SciFinder cost per session was calculated by dividing SciFinder's 2013 subscription cost by the total number of sessions at the university for the year 2013, resulting in a cost per session of $\$ 18.73$. 


\section{SciFinder Usage}

SciFinder usage was the most difficult number to calculate, as it involved some inference. Two SciFinder usage numbers were generated: "minimum usage" and "likely usage". Minimum usage was calculated as the number of students who attended a library instruction session, as the librarian actually witnessed each of them using SciFinder, plus the number of sessions activated by the librarian for preparation and demonstration purposes. This resulted in a minimum usage of 31 SciFinder sessions.

To determine likely usage for the assignment, a graph of SciFinder monthly usage for the 2013-2014 academic year (July 2013-May 2014) was generated (see Figure 1). One month was particularly anomalous: December 2013, when this assignment was due. The assumption was made that these additional SciFinder sessions were due to students researching this assignment. The "likely usage" number was therefore calculated as the number of sessions in December 2013 (572) minus the average number of sessions for the 2013-2014 academic year (322), resulting in a likely usage of 250 sessions.

Figure 1. Number of SciFinder sessions by month for the 2013-2014 academic year.

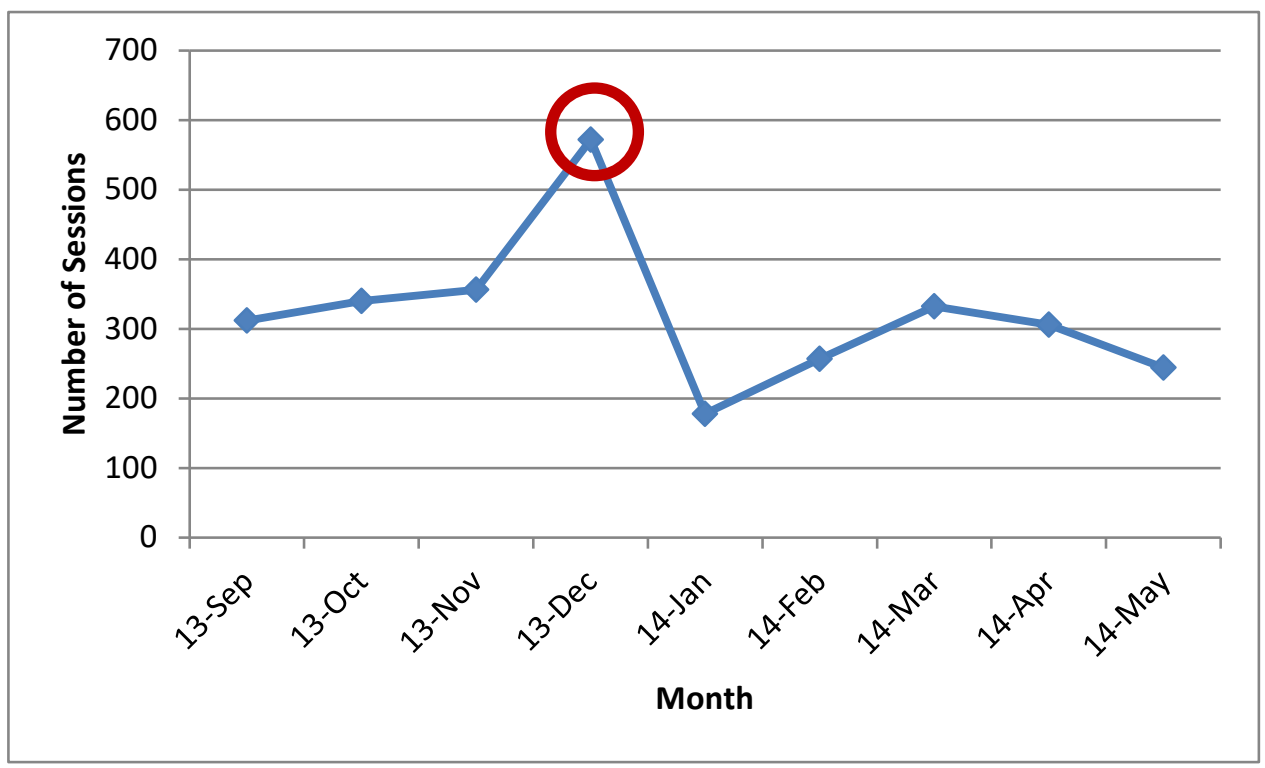




\section{Total SciFinder Cost}

Total SciFinder cost was calculated by multiplying the SciFinder cost per use by the SciFinder usage (both low and likely usage). Low SciFinder cost was $\$ 468.31$ and likely SciFinder cost was $\mathbf{\$ 4 , 6 8 5 . 1 5}$.

\section{Librarian Cost (Salary)}

One final cost to the library was that of the librarian's time. In 2013, the median salary for an academic librarian in the Midwest was $\$ 39,800$ (Maatta 2013). The librarian spent 2 hours preparing for the instruction sessions, delivered 6 separate one-hour sessions, and had 2 hours' worth of follow-up questions from students. Thus, 10 total hours of the librarian's time resulted in a total librarian cost of $\mathbf{\$ 1 9 1 . 3 5}$. It should be noted, however, that this does not include the cost of the employee's benefits, but considering that the librarian cost was the smallest of the factors contributing to total cost, it was decided to simply use salary as a baseline calculation.

\section{Results}

Taking the cost of journals, SciFinder, and the librarian, a range of possible total cost values were calculated. Adding together the actual journal cost, the minimum SciFinder usage cost, and the librarian salary, resulted in a low cost estimate of $\$ 2,972.38$. The high cost estimate was calculated using the list price of journals, the likely SciFinder usage, and the librarian salary, and resulted in a high cost estimate of $\$ 16,885.28$. The likely cost for this assignment used the actual journal cost, the likely SciFinder usage, and the librarian salary, for a total cost of $\mathbf{\$ 7 , 1 8 9 . 2 2}$. See Table 1 for a summary of 
these calculations.

Table 1. Total assignment cost and cost per student using three different calculations: low, high, and likely.

\begin{tabular}{|l|r|r|r|}
\cline { 2 - 4 } \multicolumn{1}{c|}{} & Low Cost & List Cost & Likely Cost \\
\hline Journals: & $\$ 2,312.72(78 \%)$ & $\$ 12,008.78(71 \%)$ & $\$ 2,312.72(32 \%)$ \\
\hline SciFinder: & $\$ 468.31(16 \%)$ & $\$ 4,685.15(28 \%)$ & $\$ 4,685.15(65 \%)$ \\
\hline Salary: & $\$ 191.35(6 \%)$ & $\$ 191.35(1 \%)$ & $\$ 191.35(3 \%)$ \\
\hline Total: & $\$ 2,972.38$ & $\$ 16,885.28$ & $\$ 7,189.22$ \\
\hline Cost per Student: & $\$ 56.08$ & $\$ 318.59$ & $\$ 135.65$ \\
\hline
\end{tabular}

\section{Limitations}

The biggest limitation to these calculations is the likelihood of students having only read the abstract and not accessing the actual article. This was verified in at least two cases, where students cited a particular journal, but Miami University showed no usage of that journal for the entire year of 2013. The author of this paper chooses not to explore the implications for academic integrity, but rather wants to point out that the cost for the journals is only accurate so far as the students actually accessed the full text of the article. While it is also possible that students accessed journal articles through Google or Google Scholar or some other scholarly database, it would not affect the overall cost assigned to SciFinder usage, but if these students had used SciFinder instead of an alternate source, the calculated SciFinder cost would be even higher.

Other limitations arise from the estimations that were used for cost. The SciFinder cost estimate was based on average usage across other months and the spike that resulted around the due date of this assignment. If there was another assignment 
due at the same time (for another class) that required the use of SciFinder, it would have skewed these numbers slightly, but to the best of the author's knowledge there was no such assignment. The other questionable figures arose from using Ulrichsweb as the "list price" of many of the journals, as the price listed in Ulrichsweb often represents a single subscriber's cost and not a more generalized list price.

Finally, while it is not a limitation, caution should be used in generalizing these findings to other disciplines and other classes. Scientific journals and databases are notoriously expensive, so caution should be taken if one wishes to extrapolate beyond the confines of this single study.

\section{Conclusion}

As libraries face continuing budget crunches year after year, being able to justify journal and staffing costs becomes more and more important. This study attempts to comprehensively calculate the costs associated with a single assignment in a single class. While this data cannot be directly extrapolated to a larger sample size, it nonetheless shows just how expensive even a low-level chemistry class can be. Using the methodology presented in this paper, larger studies and studies across disciplines can be conducted, providing a fuller picture of how much of the library budget is dedicated directly to serving university departments. While the library can indeed be viewed as a cost center, this study helps to show where many of those costs are directed and the value that libraries add to the curriculum. 


\section{References}

Abels, Eileen G. 1997. "Improving Reference Service Cost Studies.” Library \& Information Science Research 19 (2): 135-52. https://doi.org/10.1016/S07408188(97)90040-2.

Bosch, Stephen, and Kittie Henderson. 2015. “Whole Lotta Shakin' Goin’ On.” Library Journal 140 (7): 30-35.

Broadbent, Marianne, and Hans Lofgren. 1993. "Information Delivery: Identifying Priorities, Performance, and Value.” Information Processing \& Management 29 (6): 683-701.

Cochrane, Lynn Scott, and Carolyn Warmann. 1989. "Cost Analysis of Library Services at Virginia Polytechnic Institute and State University." In Building on the First Century: Proceedings of the Fifth National Conference of the Association of College and Research Libraries Cincinnati, Ohio, April 5-8, 1989, 55-62.

Eaton, Nancy L., and Nancy B. Crane. 1987. "Integrating Electronic Information Systems into the Reference Services Budget." The Reference Librarian 8 (19): $161-77$.

Ferguson, Anthony W., and John R. Taylor. 1980. "What Are You Doing? An Analysis of Activities of Public Service Librarians at a Medium-Sized Research Library.” Journal of Academic Librarianship 6 (1): 24-29.

Kantor, Paul B., Tefko Saracevic, and Joann D’Esposito-Wachtmann. 1995. “Studying The Cost and Value of Library Services: Final Report."

Maatta, Stephanie L. 2013. “The Emerging Databrarian.” Library Journal 138 (17): 26. Montgomery, Carol Hansen. 2002. "Print to Electronic: Measuring the Operational and Economic Implications of an Electronic Journal Collection.” Learned Publishing 15 (2): 129-36.

Spencer, Carol C. 1980. "Random Time Sampling With Self-Observation for Library Cost Studies: Unit Costs of Reference Questions." Bulletin of the Medical Library Association 68 (1): 53-57. https://doi.org/10.1002/asi.4630220303. 
"Ulrichsweb.Com." 2014. ProQuest LLC. Accessed May 24, 2014.

http://ulrichsweb.serialssolutions.com/. 